\title{
Prevalence of Extended-Spectrum Beta-Lactamases (ESBLs) and Metallo-Beta- Lactamases (MBLs) Among Healthy and Hospitalized Children in Abraka and Eku Communities, Delta State, Nigeria
}

\author{
${ }^{*}$ O. S. Egbule and E. E. Odih \\ Department of Microbiology, Delta State University, Abraka \\ [Corresponding Author: E-mail: oliviaegbule@gmail.com; : :+234(0)8062439096]
}

ABSTRACT

This study was conducted to detect the prevalence of Metallo-Beta-Lactamases (MBLs) and ExtendedSpectrum Beta-Lactamases (ESBLs) in bacterial isolates from clinical and community settings of two communities in Delta State, Nigeria. Eighty four isolates obtained from blood, urine, wound and stool of patients and community subjects were analyzed and identified by standard microbiological methods. Carbapenemase detection was carried out using modified Hodge test. EDTA-disc synergy test was used to detect MBLs production in $26.2 \%$ of the isolates. ESBLs production determined by double disc synergy test (DDST) was detected in $36.7 \%$ isolates of Escherichia coli, $37.5 \%$ of Pseudomonas aeruginosa and $75 \%$ of Klebsiella pneumoniae. Co-production of MBL and ESBL was observed in $31.8 \%$ of the isolates. The study observed 2 major troubling findings. The first is the prevalence and co-production of MBLs and ESBLS both in hospitalized patients and in isolates of healthy community children. Second, antibiotic resistant bacteria may be able to persist in the community free from the high selective pressure pervading in clinical settings. There is therefore the need for increased surveillance.

Keywords: Antibiotic resistance, Multidrug resistance, Healthy children, Beta-lactamases, Plasmids.

\section{INTRODUCTION}

The emergence of multi-drug resistant pathogenic bacteria generally considered a major clinical crisis has steadily increased over the last two decades (Gniadedkowski, 2001). Beta-lactam antibiotics are among the most employed drugs for the treatment of serious bacterial infections. The most active of this group is the carbapenems. Gram negative bacteria have developed a variety of resistance mechanisms to the beta-lactams including hydrolysis of betalactam ring by beta-lactamases, alteration in the penicillin-binding proteins, decrease in outer membrane permeability and expression of efflux pumps. The beta-lactamase enzymes including the extended spectrum beta-lactamases (ESBLs) and the carbapenemases are usually plasmid mediated and have been mainly reported in Enterobacteriaceae such as Escherichia coli, Klebsiella pneumonia and in Pseudomonas aeruginosa (Paterson and Bonomo, 2005). The ESBL enzymes confer resistance to the cephalosporins and monobactams but are inhibited by $\beta$-lactam inhibitors (Paterson and Bonomo, 2005). The carbapenems are reliably active against bacteria harbouring ESBLs, as such carbapenems are often considered as the treatment option of last resort against infections caused by multidrug-resistant Enterobacteriaceae.

The production of metallo-beta-lactamases is a major problem in the therapy of clinically ill patients. Acquired MBL genes are located on the integron which enable wide spread dissemination (Walsh et al., 2005). MBL and ESBL-producing Enterobacteriaceae are prevalent in the hospital setting (Brolund, 2014; Dortet et al., 2014). However, there have been reports of their emergence and spread in the community as well (Smith et al., 2004; Pitout et al., 2005). Their presence in the community greatly increases the risk of other individuals becoming carriers via human-to-human transmission (Levin, 2001). It is therefore important to monitor the prevalence of 
organisms producing these enzymes in the community to prevent further spread.

This study was thus designed to investigate the prevalence of organisms producing MBLs and ESBLs in hospitals and in some communities of Delta State, Nigeria.

\section{MATERIALS AND METHODS}

Ethical approval for the study was granted by the ethical committee of Baptist Medical Center, Eku and General Hospital Abraka, Delta State, while consent for participation was sought through the school authorities, parents and hospitalized patients or their care givers before samples were collected.

\section{Sample Collection}

Stool samples were collected from 100 healthy children attending primary schools of in Abraka and Eku communities in Delta State. The stool samples were collected in dry sterile containers and transported immediately in ice packs to the laboratory for analysis. A total of 120 clinical specimens of wound, blood, and urine were obtained from hospitalized patients in General Hospital Abraka and Baptist Medical Center, Eku. Wounds were cleaned with normal saline solution prior to collection and sterile swab sticks were used to obtain wound samples. Midstream urine was collected from patients in sterile containers while blood samples were collected (with the help of trained health personnel) by venipuncture using $10 \mathrm{~cm}^{3}$ syringe after cleaning with an alcohol swab and finally dispensed into EDTA treated sample containers.

\section{Isolation and Identification of Esherichia coli, Pseudomonas aeruginosa and Klebsiella pnuemoniae}

Blood samples were inoculated into Brain Heart Infusion broth and were incubated overnight. Blind sub-culture was done onto fresh $5 \%$ sheep blood agar and MacConkey agar. A negative result was followed up by examining the broth daily and doing a final sub-culture at the end of the $7^{\text {th }}$ day or at the appearance of turbidity. Urine samples were inoculated onto cystine lactose electrolyte deficient (CLED) agar and MacConkey agar. Wound swabs were inoculated onto MacConkey agar and Blood agar. Stool samples were inoculated onto MacConkey agar plates. The plates were incubated for $24 \mathrm{~h}$ at $37^{\circ} \mathrm{C}$ under aerobic conditions. Colonies that appeared mucoid, lactose fermenting on MacConkey, gray or yellow on blood and CLED agar respectively were suggestive of E.coli and K.pnuemoniae.Also,mucoid and nonlactose fermenting colonies on MacConkey agar,gray on blood agar were suggestive of $P$. aeruginosa. These colonies were sub cultured onto nutrient agar plates and incubated for $24 \mathrm{~h}$ at $37^{\circ} \mathrm{C}$ for the isolation of pure cultures. All isolates were further screened using conventional biochemical tests which include Triple sugar iron (TSI), IMViC, urease production, catalase, oxidase and motility (Table 1). Presumptive $P$. aeruginosa was also characterized on its ability to grow at $42^{\circ} \mathrm{C}$ (Cheesbrough, 2006).

\section{Screening of Isolates for Carbapenemase Production}

Carbapenemase production was detected in each of the isolates using the Modified Hodge Test method (CLSI, 2009; Walsh et al., 2011). A 0.5 McFarland dilution of Escherichia coli ATCC 25922 in $5 \mathrm{ml}$ peptone water was prepared and diluted to $1: 10$ by adding $0.5 \mathrm{ml}$ of the 0.5 McFarland E. coli ATCC 25922 to $4.5 \mathrm{ml}$ peptone water. The 1:10 dilution of $E$. coli ATCC 25922 was streaked using a sterile cotton swab on the surface of a Mueller-Hinton agar (MHA) plates. The plates were allowed to dry for about 10 minutes and a $10 \mu \mathrm{g}$ meropenem disk (Oxoid, England) was placed at the center of the plate and the test strain was streaked from the edge of the disk to the periphery of the plate in four different directions. Thereafter, the plate was incubated overnight at $37^{\circ} \mathrm{C}$. The presence of a cloverleaf-like indentation of $E$. coli ATCC 25922 growing along the test isolate growth streak within the disc diffusion zone was considered as a positive result. 


\section{Metallo- $\beta$ - Lactamases Detection}

EDTA-disc synergy test was used to detect MBL production in each of the isolates (CLSI, 2009; Walsh et al., 2011). Overnight suspensions of carbapenemase-producing isolates adjusted to a $0.5 \mathrm{McFarland}$ standard were streaked on the surface of MHA plates using sterile cotton swabs. The inoculated plates were allowed to sit for

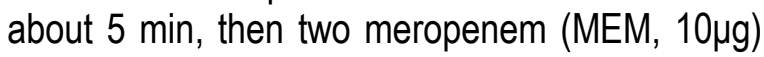
(Oxoid, England) discs, one impregnated with EDTA and the other without EDTA were placed on the surface of the MHA at a distance of about $20 \mathrm{~mm}$ apart. The plates were incubated for $24 \mathrm{~h}$ at $37^{\circ} \mathrm{C}$. Zones of inhibition were recorded after $24 \mathrm{~h}$ of incubation. Organisms that showed difference in diameter of zone of inhibition by $\geq 7 \mathrm{~mm}$ on the MEM containing EDTA and MEM alone were confirmed for the production of MBLs.

\section{ESBLs Detection Using Double Disc Synergy Test}

Overnight suspensions of the test organisms adjusted to a 0.5 McFarland standard were streaked on the surface of freshly prepared Muller Hinton agar plates using sterile cotton swabs.
Amoxicillin-clavulanic acid discs (containing amoxicillin $20 \mu \mathrm{g} /$ clavulanic acid $10 \mu \mathrm{g}$ ) were placed at the center of the inoculated plates. Ceftazidime $(30 \mu \mathrm{g})$ and Cefotaxime $(30 \mu \mathrm{g})$ discs (Oxoid, England) were each placed $20 \mathrm{~mm}$ centre apart from the Amoxicillin-clavulanic acid disc. The plates were then incubated for $24 \mathrm{~h}$ at $37^{\circ} \mathrm{C}$. Organisms that showed an increase in zone of inhibition around any of the cephalosporins toward the amoxicillin-clavulanic acid disc by $\geq 5 \mathrm{~mm}$ were confirmed for the production of ESBLS.

\section{RESULTS}

A total of 84 isolates obtained from stool (59), Urine (19), wound (3) and blood (3), were screened for metallo-beta-lactamase and extended spectrum beta-lactamase production. Forty $(47.62 \%)$ were positive for carbapenemase production. Klebsiella pneumoniae $(62.50 \%)$ had the highest prevalence, followed by Pseudomonas aeruginosa (50.00\%). Escherichia coli had the lowest prevalence of $45.59 \%$ (Table 2).

Table 1: Biochemical tests for the identification of Escherichia coli, Klebsiella pnuemoniae and Pseudomonas aeruginosa

\begin{tabular}{llll}
\hline $\begin{array}{l}\text { Biochemical } \\
\text { characteristics }\end{array}$ & Escherichia coli & Klebsiella pnuemoniae & $\begin{array}{l}\text { Pseudomonas } \\
\text { aeruginosa }\end{array}$ \\
\hline Indole & + & - & - \\
Methyl red & + & - & - \\
Voges-Proskauer & - & + & - \\
Citrate & - & + & + \\
Urease & - & + & - \\
Catalase & + & + & + \\
Oxidase & - & - & + \\
Motility & + & - & + \\
Hydrogen sulfide & - & - & - \\
D-glucose (acid/gas) & $+/+$ & $+/+$ & $-/-$ \\
Sucrose & + & + & - \\
Lactose & + & + & - \\
\hline
\end{tabular}

Key: + = test positive; - = test negative 
Egbule and Odih: Prevalence of Extended-Spectrum Beta-Lactamases (ESBLs) and

Table 2: Occurrence of carbapenemase producer among bacterial isolates

\begin{tabular}{llll}
\hline Isolates & No of isolates screened & $\begin{array}{l}\text { No of isolates producing } \\
\text { carbapenemase (\%) }\end{array}$ \\
\hline Escherichia coli & 68 & $31(45.59)$ \\
Pseudomonas aeruginosa & 8 & $4(50.00)$ \\
Klebsiella pneumonia & 8 & $5(62.50)$ \\
Total & 84 & $40(47.62)$ \\
\hline
\end{tabular}

The number of MBL producers in this study was $22(26.19 \%)$. The highest prevalence of MBL production was observed in Klebsiella pneumoniae $(37.50 \%)$ followed by $E$. coli $(26.47 \%), \quad$ and Pseudomonas aeruginosa $(12.50 \%)$. Wound samples had the highest prevalence $(66.67 \%)$ of MBL producers followed by urine $(26.32 \%)$ and stool $(25.42 \%)$ samples. No MBL producer was observed in blood samples. The highest ESBLs producer, was observed in urine samples (63.16\%), followed by stool samples $(33.90 \%)$ while both blood and wound samples had prevalence rates of $33.33 \%$. (Table 3 )

Table 3: Distribution of ESBL producers according to sample

\begin{tabular}{lllllll}
\hline & & Urine & Wound & Blood & Stool & Total \\
\hline E. coli & $\begin{array}{l}\text { Number } \\
\text { screened }\end{array}$ & 6 & 2 & 1 & 59 & 68 \\
& $\begin{array}{l}\text { ESBL } \\
\text { producers }\end{array}$ & $4(66.67)$ & $0(0.00)$ & $1(100.00)$ & $20(33.90)$ & $25(36.76)$ \\
& $\begin{array}{l}\text { MBL } \\
\text { producers }\end{array}$ & $1(16.67)$ & $2(100.00)$ & $0(0.00)$ & $15(25.42)$ & $18(26.47)$ \\
$\begin{array}{l}\text { Pseudomonas } \\
\text { aeruginosa }\end{array}$ & $\begin{array}{l}\text { Number } \\
\text { screened }\end{array}$ & 6 & 1 & 1 & 0 & 8 \\
$\begin{array}{l}\text { ESBL } \\
\text { producers }\end{array}$ & $2(33.33)$ & $1(100.00)$ & $0(0.00)$ & $0(0.00)$ & $3(37.50)$ \\
Klebsiella pneumonia & $\begin{array}{l}\text { MBL } \\
\text { producer } \\
\text { Number }\end{array}$ & $1(50.00)$ & $0(0.00)$ & $0(0.00)$ & $0(0.00)$ & $1(12.50)$ \\
& $\begin{array}{l}\text { screened } \\
\text { ESBL } \\
\text { producers }\end{array}$ & $6(85.71)$ & $0 .(0.00)$ & $0(0.00)$ & $0(0.00)$ & $6(75.00)$ \\
TOTAL & $3(42.85)$ & $0(0.00)$ & $0(0.00)$ & $0(0.00)$ & $3(37.50)$ \\
$\begin{array}{l}\text { MBL } \\
\text { producer } \\
\text { Number } \\
\text { screened }\end{array}$ & 19 & 3 & 3 & 59 & 84 \\
\hline $\begin{array}{l}\text { ESBL } \\
\text { producers } \\
\text { MBL } \\
\text { producer }\end{array}$ & $12(63.16)$ & $1(33.33)$ & $1(33.33)$ & $20(33.90)$ & $34(40.48)$ \\
\hline
\end{tabular}


Table 4: Distribution of MBL and ESBL Producers Amongst Community and Clinical Isolates

\begin{tabular}{lccc}
\hline Isolates & $\begin{array}{l}\text { Number of isolates } \\
\text { screened }\end{array}$ & $\begin{array}{l}\text { Number of MBL positive } \\
\text { isolates (\%) }\end{array}$ & $\begin{array}{l}\text { Number of ESBL- } \\
\text { positive isolates (\%) }\end{array}$ \\
\hline Community & 59 & $15(25.42)$ & $20(33.90)$ \\
Clinical & 25 & $7(28.00)$ & $14(56.00)$ \\
Total & 84 & $22(26.19)$ & $34(40.48)$ \\
\hline
\end{tabular}

Table 5: Occurrence of ESBL producers among MBL-producing isolates

\begin{tabular}{lcc}
\hline \multicolumn{1}{c}{ Isolates } & No of MBL-producing isolates & $\begin{array}{c}\text { No of MBL isolates producing } \\
\text { ESBLs (\%) }\end{array}$ \\
\hline E. coli & 18 & $3(16.67)$ \\
Pseudomonas aeruginosa & 1 & $1(100.00)$ \\
Klebsiella pneumoniae & 3 & $3(100.00)$ \\
\hline TOTAL & $\mathbf{2 2}$ & $\mathbf{7 ( 3 1 . 8 2 )}$ \\
\hline
\end{tabular}

The overall ESBLs prevalence was $40.48 \%$, with clinical isolates producing more ESBLs $(56.00 \%)$ than isolates obtained from the community $(33.90 \%)$ Results are shown in Table 4. Among the isolates found to produce MBLs, $7(28.00 \%)$ isolates also produced ESBLs. Co-production of ESBL was observed in $100 \%$ of MBLpositive Klebsiella

pnuemoniae and Pseudomonas aeruginosa (Table 5).

\section{DISCUSSION}

The ability to produce beta-lactamase enzymes is the major cause of bacterial resistance to betalactam antibiotics. The results of our study indicate ESBLs and MBLs were prevalent in both clinical and community isolates. The observed prevalence of $25 \%$ and $33 \%$ in MBLs and ESBLs respectively among healthy children is a call for the need to strengthen the fields of sanitation amongst children in primary schools in Delta State. The emergence and dissemination of these beta-lactamase enzymes thus decreased the usefulness of beta-lactam drugs in therapy.
Reports on MBLs and ESBLs production have been documented in clinical settings by different authors (Toleman et al., 2005; Marchiaro et al., 2005; Manoharan et al., 2010; Kaleem et al., 2010; Enwuru et al., 2011; Egbebi and Famurewa, 2011; Yusuf et al., 2012).

Reports on community-onset are gradually on the increase (Walsh et al., 2005; Pitout and Laupland, 2008). Community children with no history of travel to endemic countries or recent history of hospitalization have been found to harbor isolates carrying $\mathrm{ESBL}$ and $\mathrm{MBL}$ genes (Logan and Bonomo, 2016). The cause of community-acquired infections is not yet clear, however cross contamination due to poor hand washing practice amongst school children is a possible route, allowing the transmission of bacteria to and among the children via physical contact and during consumption of food. Beta lactamases are usually encoded on plasmids and as such can be easily transmitted between different bacterial species by horizontal gene transfer. Asymptomatic children may therefore be 
healthy carriers of MBL or ESBL-producing Enterobacteriaceae (Viau et al., 2012; Yaffee et al., 2015).

A high prevalence of $25 \%$ among community isolates is worrying. Treatment of severe clinical and community acquired infections rely on carbapenems (Wong-Beringer, 2001; Falagas and Karageorgopoulos, 2009; Paterson, 2010). They are thus considered the first choice for treatment of patients infected with MBL or ESBLproducing Enterobacteriaceae. Isolates producing MBL were resistant to the carbapenem; meropenem as indicated by carpabenamase production tests. The situation could complicate therapy if and when the community children become ill.

Klebsiella pneumoniae $(75.00 \%)$ was the most prevalent ESBL producer in this study (Table 2). Klebsiella spp. are opportunistic pathogens and primarily attack immuno-compromised individuals who are hospitalized. Egbebi and Famurewa (2011) conducted a study on the prevalence of ESBLs in Klebsiella spp. across several States in Nigeria and reported high prevalence rates of between $43.6 \%-72.5 \%$ in Lagos, Ondo, Ekiti and Osun States. Several authors have also found Klebsiella spp. to be ESBL producers in their studies (Livrelli et al., 1996; Lal et al., 2007). Resistance of Klebsiella spp. may be due to the presence of capsule that gives protection to the cells and presence of multidrug resistance efflux pump. They also spread easily and are efficient at acquiring and disseminating resistance plasmid (Chaudhary and Aggarwal, 2004; Gruteke, 2003; Yusha'u, 2010).

One important finding in this study is that of the 22 isolates positive for MBL production, 7 (31.82\%) also co-produced ESBLs with $100 \%$ of the Pseudomonas aeruginosa and Klebsiella spp. expressing co-production (Table 5). This may mean an increase in horizontal transfer of resistance trait, commonly observed amongst plasmid carrying MBL or ESBL-producing pathogens which often demonstrate additional mechanisms that give rise to co-resistance to many other antibiotics (Paterson, 2004), depleting the choice of therapy.

\section{CONCLUSION}

The findings in this study have demonstrated the presence of MBL- and ESBL-producing bacteria strains from community and hospital subjects within Delta State, Nigeria. It also highlights an emerging problem;that healthy individuals may be reservoirs of resistant bacteria in the community, emphasizing the importance of surveillance.

\section{REFERENCES}

Brolund, A. (2014). ESBL-producing Enterobacteriaceae from a Nordic perspective. Infection Ecology and Epidemiology 4: doi:10.3402/iee.v4.24555.

Chaudhary, U. and Aggarwal, R. (2004). Extended Spectrum Beta-Lactamases (ESBL) - An Emerging Threat to Clinical Therapeutics. Indian Journal of Medical Microbiology; 22(2): 75-80.

Cheesbrough, M., (2006). District Laboratory Practice in Tropical Countries. 2nd Edn., Cambridge University Press, Cambridge, UK., ISBN-13: 9781139449298.

Clinical and Laboratory Standards Institute (CLSI). (2009). Performance standards for antimicrobial susceptibility testing; 19th informational supplement. CLSI document M100-S19. Wayne, PA: CLSI.

Dortet, L., Poirel, L. and Nordmann, P. (2014). Worldwide dissemination of the NDMtype carbapenemases in Gram-negative bacteria. Biomedical Research International, 2014:249856. https://doi.org/10.1155/2014/249856

Egbebi, A. and Famurewa, O. (2011). Prevalence of Extended Spectrum Beta-Lactamase (ESBL)

Production among Klebsiellalsolates in Some Parts of South West Nigeria. Journal of Microbiology and Biotechnology Research, 1(2): 64-68. 


\section{Nigerian Journal of Basic and Applied Science (June, 2020), 28(1): 07-14}

Enwuru, N. V., Enwuru, C. A., Ogbonnia, S. O. and Adepoju-Bello, A. A. (2011). MetalloB-Lactamase Production by Escherichia coli and Klebsiella spp. Isolated from Hospital and Community Subjects in Lagos, Nigeria. Nature and Science, 11: 1-5.

Falagas, M. E. and Karageorgopoulos, D. E. (2009). Extended-Spectrum BetaLactamase-Producing Organisms. Journal of Hospital Infection, 73: 345-354.

Gniadedkowski, M. (2001). Evolution and epidemiology of extended-spectrum $\beta$-lactamases (ESBLs) and ESBL producing microorganisms. Clinical Microbiology and Infection, 7(11): 597608.

Gruteke, P., Goessens, W., Gils, J. V., Peerbooms, P., Toom, N. L. and SantenVerheuvel M. V. (2003). Pattern of Resistance Associated with Integrons, the Extended-Spectrum â lactamase SHV-5 Gene and a Multidrug Efflux Pump of Klebsiella pneumoniae Causing a Nosocomial Outbreak. Journal of Clinical Microbiology, 41(3): 1161-1166.

Kaleem, F., Usman, J., Hassan, A. and Khan, A. (2010). Frequency and Susceptibility Patterns of Metallo-Beta-Lactamase Producers in a Hospital in Pakistan. Journal of Infections in Developing Countries, 4(12): 810-813.

Lal, P., Kapil, A., Das, B. K. and Sood, S. (2007). Occurrence of TEM and SHV gene in extended spectrum beta lactamases (ESBLs) producing Klebsiella spp. isolated from a tertiary care hospital, Indian Journal of Medical Microbiology, 125: 173-178.

Levin, B. R. (2001). Minimizing potential resistance: a populationdynamics view. Clinical Infectious Diseases, 33: 161-169.

Livrelli, V., Champs, C. D., Martino, P. D., Michaud, A. D., Forestier, C. and Joly, B. (1996). Adhesive Properties and
Antibiotic

Resistance of Klebsiella, Enterobacter and Serratia C linical Isolates Involved in Nosocomial Infections, Journal of Clinical Microbiology, 34(8):1963-1969.

Logan, L.K and Bonomo, R.A(2016). Metallo- $\beta$ Lactamase (MBL)-Producing Enterobacteriaceae in United States children. Open Forum Infectious Disease, 3(2); 090-095.

Manoharan, A., Chatterjee, S. and Mathur, D. (2010). Detection and characterization of metallo $\quad \beta \quad$ lactamases producing Pseudomonas aeruginosa. Indian Journal of Microbiology, 28:241244.

Marchiaro, P., Mussi, M.A., Ballerini, V., Pasteran, F., Viale, A.M. and Vila, A.J. (2005). Sensitive EDTA based microbiological assay for detection of metallo $\beta$ lactamase in non fermentative Gram negative bacteria. Journal of Clinical Microbiology, 43:5648-5652.

Paterson, D. L. (2000). Recommendation for treatment of severe infections caused by Enterobacteriaceae producing extendedspectrum beta-lactamases (ESBLs). Clinical Microbiology and Infection, 6(9): 460-463.

Paterson, D. L. (2004). Collateral damage from cephalosporin or quinolone antibiotic therapy. Clinical Infectious Diseases, 38: 341-345.

Paterson, D. L. (2010). Infections with organisms producing extended spectrum $\beta$ lactamase. In Antimicrobial resistance Beyond the break point. Basel, Karger. pp. 21-34.

Paterson, D. L. and Bonomo, R. A. (2005). Extended-spectrum beta-lactamases. a clinical update. Clinical Microbiology Reviews, 18: 657-686.

Pitout, J. D. and Laupland, K. B. (2008). Extended-spectrum beta-lactamaseproducing Enterobacteriaceae: an emerging public-health concern. Lancet Infectious Diseases, 8(3):159-66. 
Pitout, J. D., Nordmann, P., Laupland, K. B. and Poirel, L. (2005). Emergence of Enterobacteriaceae producing extendedspectrum beta-lactamases (ESBLs) in the community. Journal of Antimicrobial Chemotherapy, 56(1): 52-59.

Smith, D.L., Dushoff, J., Perencevich, E. N., Harris, A. D. and Levin, S. A. (2004). Persistent colonization and the spread of antibiotic resistance in nosocomial pathogens: resistance is a regional problem. Proceedings of the National Academy of Science USA, 101: 37093714.

Toleman, M. A., Biedenbach, D., Bennet, D. M. C., Jones, R.N. and Walsh, T. R. (2005). Italian metallo $\beta$ lactamase: a national problem? Report from the SENTRY Antimicrobial Surveillance Program. Journal of Antimicrobial Chemotherapy, 55:61-70.

Viau RA, Hujer AM, Marshall (2012). "Silent" dissemination of Klebsiella pneumoniae isolates bearing $K$. pneumoniaecarbapenemase in a longterm care facility for children and young adults in Northeast Ohio. Clinical Infectious Diseases, 54:1314-1321.

Walsh, T. R., Janis, W., David, M. L. and Mark, A. T. (2011). Dissemination of NDM-1 positive bacteria in the New Delhi environment and its implications for human health: an environmental point prevalence study. The Lancet Infectious Diseases, 20:11-13.
Walsh, T. R., Toleman, M. A., Poirel, L. and Nordmann, P. (2005). Metallo-Betalactamases: the quiet before the storm? Clinical Microbiology Reviews, 18:306-325.

Wong-Beringer, A. (2001). Therapeutic challenges associated with extendedspectrum beta-lactamsproducing Escherichia coli and Klebsiella pneumoniae. Pharmacotherapy, 21: 58392.

Yaffee, A.Q., Roser, L. and Daniels, K.(2015). Notes from the field: Verona integronencoded metallo-beta-lactamaseproducing carbapenem-resistant Enterobacteriaceae in a neonatal and adult intensive care unit-Kentucky. Morbidity and Mortality Weekly Report,65:190.

Yusha'u, M. M., Kumurya, A. S. and Suleiman, L. (2010). Prevalence of Extended spectrum â lactamases among Enterobacteriaceae in Murtala Mohammed specialist hospital, Kano. Journal of Pure and Applied Sciences, 3(1):169- 172.

Yusuf, I., Yusha'u, M., Getso, M., Yahaya, H., Bala, J., Aliyu, I. and Haruna, M. (2012). Detection of Metallo-Beta-Lactamases among Gram Negative Bacterial Isolates from MurtalaMuhammed Specialist Hospital, Kano and Almadina Hospital Kaduna, Nigeria. Bayero Journal of Pure and Applied Sciences, 5(2): 84-88. 